\title{
No mires nuestros pecados, sino la fe de la Iglesia*
}

\section{Víctor Codina, S.J., profesor emérito de la Universidad Católica Boliviana de Cochabamba}

Antes de abordar este tema, que es inmenso, oceánico, quisiera esclarecer de qué fe y de qué Iglesia hablamos.

¿De qué $f e$ hablamos? No hablamos directamente de la fe como dogmas y verdades, como contenidos, por importantes y necesarios que sean, para no hacer de la fe un grito en el vacío. No hablamos directamente de la fides quae credimus, la fe de los credos y de los dogmas, sino de la fides qua creditur, de la actitud creyente, de la apertura, confianza y esperanza en el Dios que da existencia a lo que no existe y da vida a los muertos $(\mathrm{Rm} \mathrm{4,17).} \mathrm{Hablamos} \mathrm{de} \mathrm{la}$ fe que se apoya en Dios como roca firme de la existencia, de la fe que se opone al miedo, de la fe bíblica que es el amén al Dios que siempre camina con su pueblo y constantemente le repite: "No tengan miedo, yo estoy con ustedes". Evidentemente, en la práctica creyente la fe como actitud y como contenido son inseparables, pero metodológicamente partiremos de la fe con la que creemos.

¿De qué Iglesia hablamos? De la Iglesia Pueblo de Dios, no solo de la Iglesia institución que mantiene fielmente la doctrina. Hablamos del Pueblo de Dios que posee el sentido de la fe, el sensus fidei, sensus fidelium, por la unción del Espíritu y el bautismo, una fe que es infalible cuando se adhiere a la tradición universal de la Iglesia, como recuerda el Vaticano II ( $L G 12)$.

El cardenal John Henry Newman, en su tratado Sobre la consulta de los fieles en cuestiones de fe, afirma que en el siglo IV, en plena disputa arriana, no fueron los obispos ni los sínodos los que mantuvieron la fe verdadera, sino los creyentes sencillos ${ }^{1}$.

* Ponencia dada el 12 de marzo de 2013 en la Semana Teológica del ITER (Instituto de Teología para Religiosos, Universidad Católica Andrés Bello, de Caracas).

1. H. Newman, Consulta a los fieles en materia doctrinal, Salamanca, 2001; cf. W. Kasper, El Evangelio de Jesucristo, Santander, 2012, p. 234. 
Esta fe que es don de Dios es la que se abre y acoge la Palabra, nos impulsa por el Espíritu a llamar a Dios Abbá, Padre (Rom 8, 15; Gal 4, 6), se celebra y vive comunitariamente en la Iglesia, muy especialmente en la eucaristía, se testimonia en la vida y se convierte en servicio fraterno a la sociedad, sobre todo a los más excluidos. Dicho en forma clásica, la fe es kerigma y martyria, leiturgia y diakonía, todo ello vivido en comunión, en koinonía.

Ahora bien, esto supuesto y teniendo en cuenta que la fe es histórica, que la Iglesia está en camino hacia el reino, en tensión entre el ya-sí y el todavía-no del reino consumado, surge la pregunta por el estado y situación de la fe en la Iglesia católica de hoy y más concretamente en la Iglesia de América Latina. El tema es tan amplio e interdisciplinar que nos limitaremos a ofrecer algunos de los rasgos más característicos de la fe en el mundo occidental desarrollado y en el Tercer Mundo, específicamente en América Latina.

\section{El mundo occidental desarrollado}

1.1. El mundo occidental desarrollado, nordatlántico, de tradición cristiana, concretamente el mundo europeo (España, Francia, Países Bajos, Alemania...) y el mundo norteamericano (Estados Unidos y, sobre todo, Canadá) viven una profunda secularización y crisis de fe, con expresiones diversas, más cercanas actualmente a la indiferencia y al agnosticismo que a los ateísmos clásicos de los siglos XIX y XX.

Los síntomas de esta crisis son evidentes desde el punto de vista sociológico: disminución de la praxis dominical y sacramental, templos medio vacíos, con personas jubiladas y sin jóvenes, muchos templos convertidos en museos para turistas o en salas de concierto, descenso de vocaciones al ministerio y a la vida religiosa, silencio de Dios en los medio de comunicación social, en la vida pública e incluso en los entierros, críticas constantes a la Iglesia institución, a sus escándalos sexuales y financieros, cisma silencioso de millones que abandonan la Iglesia, una vida que se siente satisfecha e instalada en la finitud, con el consumo, con el carpe diem cotidiano, una vida cerrada a la trascendencia, muy preocupada por la salud, el cuerpo, la comida, el relax, el bienestar y el alto standing.

J. M. R. Tillard se preguntaba hace algunos años si seremos los últimos cristianos, algo que ya sucedió en la Iglesia nordafricana, hoy musulmana, después de la brillante época de Cipriano y Agustín. Rahner afirma que los cristianos del siglo XXI serán místicos o no serán cristianos. W. Kasper dice que el Vaticano II no abordó suficientemente la cuestión de Dios. Pablo VI, poco después del Vaticano II, dijo que la Iglesia debía responder no ya a la pregunta: "Iglesia ¿qué dices de ti misma?", sino a la pregunta: "Iglesia ¿qué dices de Dios?". Juan Pablo II habló de nueva evangelización, sobre todo pensando en las Iglesias de vieja cristiandad hoy descristianizadas (Redemptoris missio 33). Benedicto 
XVI escribe que la barca de la Iglesia se tambalea en medio de la tempestad ${ }^{2}$ y proclama el año de la fe (Porta fidei), pensando en las Iglesias del mundo occidental moderno. Se habla de silencio de Dios, de eclipse de Dios, de noche oscura no solo para personas místicas, sino como algo generalizado.

La pregunta es cómo se ha llegado a esta situación. La respuesta es compleja y múltiple, pero podemos afirmar que en gran parte es debida a la irrupción de la modernidad ilustrada, de la llamada primera Ilustración que ha llevado a atreverse a pensar (el sapere aude de Kant), a emanciparse de la religión y confiar en la razón. Como ya afirmaba Troeltsch, la historia es el gran problema de la Iglesia. La afirmación del cardenal Martini en su testamento de que la Iglesia lleva 200 años de retraso sería una confirmación de la tesis de Troeltsch: a la Iglesia le cuesta mucho seguir el ritmo de la historia.

La revolución científica, política, cultural, industrial e informática de la sociedad ha operado un giro copernicano en el ambiente cultural y religioso. Hay una nueva imagen del mundo, de la humanidad, de la historia, una sospecha ante la religión y el mundo teónomo, se vive una secularización de la realidad, una muerte del dios premoderno, de la tradición religiosa de la cristiandad medieval, una ruptura entre la realidad social, política, científica, económica y el mundo de la fe. Vivimos no solo un cambio de época, sino un cambio de tiempo axial, en formulación de K. Jaspers (Origen y meta de la historia), en que ha caído una concepción religiosa típica de los pueblos agrícolas que provenía del neolítico, centrada en el templo, el sacerdote y el sacrificio. La cristiandad agoniza, aunque sea una agonía lenta. Vivimos un terremoto, un tsunami cultural y religioso.

Ciertamente el Vaticano II intentó instaurar un diálogo con la modernidad ilustrada, pasó del anatema al diálogo, reconoció la legítima autonomía de la creación, la libertad religiosa, que los pastores no tienen siempre la respuesta a las cuestiones urgentes del mundo de hoy. Pablo VI reconoció que los principios básicos de la Revolución francesa, libertad, fraternidad e igualdad, en el fondo eran evangélicos. Juan Pablo II escribió la encíclica Fides et ratio sobre la mutua relación entre razón y fe. Benedicto XVI habló con frecuencia de la racionalidad de la fe. Sin embargo, el mundo occidental avanza cada vez más rápidamente hacia una descristianización, hacia una era postcristiana.

1.2. El análisis anterior sería incompleto si no reconociéramos algunos datos significativos. Existe una minoría de cristianos que han hecho de esta crisis de fe un kairós para vivir el seguimiento de Jesús de forma libre, consciente y responsable, con participación comunitaria y eclesial.

2. J. Ratzinger, Jesús de Nazaret. De la entrada a Jerusalén hasta la Resurrección, Madrid, 2011, p. 339. 
Otros viven una creencia sin pertenencia eclesial, debido al antitestimonio de la Iglesia institucional, por su magisterio moral y bioético, por el rechazo de un cristianismo burgués que ha pintado la vida mundana con colores cristianos, pero que no ha transformado las estructuras injustas de la sociedad opulenta, neocapitalista, colonial y explotadora de la tierra, una sociedad tantas veces hipócrita, que invoca la paz, pero vende armas a los pueblos en guerra... La Iglesia es para muchos cada vez menos creíble, aunque siguen atrayendo el Evangelio y Jesús de Nazaret. El éxito editorial de los libros de J. A. Pagola en el mundo hispano puede ser un indicio de ello.

Otros grupos, seguramente cada vez más numerosos, tienden a volver a la situación preconciliar de la Iglesia de la cristiandad con un fundamentalismo religioso, cuyo caso extremo sería el movimiento suscitado por Lefebvre, pero que marca también el estilo de algunos de los llamados nuevos movimientos eclesiales que, asumiendo elementos de modernidad, mantienen en el fondo una postura tradicionalista.

Quizás lo más notable y nuevo es el surgimiento de diferentes grupos que sienten nostalgia de la trascendencia y buscan una espiritualidad más allá de las instituciones religiosas y más allá de la misma fe cristiana. J. B. Metz ha descrito en un famoso sorites este proceso: se ha pasado de Iglesia no pero Cristo sí, a Cristo no pero Dios sí, para ir luego a religión sí, pero Dios no y finalmente llegar a afirmar espiritualidad sí, religión no. Se busca ahora una espiritualidad que vaya más allá de las creencias, de religiones y de dioses, pero que en medio de su ambigüedad y de su tendencia a una nebulosa esotérica, esta búsqueda de espiritualidad manifiesta la verdad de las palabras de Agustín: "Nos hiciste, Señor, para ti y nuestro corazón estará inquieto hasta que descanse en ti"’3.

Pero añadamos a lo anterior que algunos grupos no creyentes, sobre todo de jóvenes, tienen una gran sensibilidad hacia la justicia, la solidaridad, el Tercer Mundo, la ecología y los excluidos. No están lejos del reino de los cielos.

Finalmente, hay algunos grupos de personas que quizás no han abandonado totalmente la fe, pero en todo caso sí su pertenencia a la Iglesia y desean volver a ella. Son los que regresan o, mejor, los que reinician y recomienzan el camino de la fe...

\section{América Latina}

Si miramos ahora la situación de la fe en el Tercer Mundo, y muy concretamente en América Latina, veremos que hay una gran diferencia e incluso contraste con el panorama del mundo moderno que hemos expuesto. Aunque esta diferencia tiende con el tiempo a diluirse paulatinamente, no se puede

3. S. Agustín, Confesiones I, 1. 
considerar que lo que ha sucedido en el mundo occidental acontecerá también y de igual modo en el Tercer Mundo. Europa no es la medida de todas las cosas e ideologías, tampoco del sentido religioso y de la fe cristiana.

Latinoamérica es un continente pobre y profundamente religioso, con un gran sentido del misterio, de lo sagrado, de la trascendencia, en parte debido a sus raíces religiosas y espirituales originarias. Esta religiosidad radical aceptó mayoritariamente la fe cristiana, a pesar de las contradicciones y ambigüedades de la primera evangelización, tridentina y unida a la conquista. Hoy es un continente mayoritariamente de cristianos bautizados.

Pero a todo ello se añade un elemento bíblico y teológico demasiado olvidado: a los sencillos y pobres han sido revelados los misterios del reino (Lc 10, 21; Mt 11, 25). Hay una misteriosa connaturalidad entre su vida sencilla y pobre y los valores evangélicos, entre su fides qua y su fides quae, entre su vida y los valores del reino. Su pobreza y marginación los abre al Señor, su único poder es el Señor, es lo único que les queda. Por esto cuando dicen: "Si Dios quiere", "sea la voluntad de Dios", "primero Dios", "Diosito nos acompaña siempre", expresan una fe profunda, una confianza total en Dios. Esta actitud de fe les da fuerza para luchar por la vida, para no suicidarse colectivamente, para resistir, cantar, reír, casarse y tener hijos, celebrar y gozar de la vida cotidiana como don de Dios, creyendo que para Dios todo es posible, esperando siempre un mañana mejor. Ellos son los rostros sufrientes de Cristo, según Puebla (Puebla 31-39); el pueblo crucificado, según Ellacuría.

Pero esta fe que se constituye como el substrato común de América Latina tiene diversas manifestaciones y expresiones, a veces incluso contradictorias. Hay un gran pluralismo religioso y de creencias en Latinoamérica.

2.1. La religiosidad popular expresa de forma clara la simbiosis entre las culturas y religiones originarias y la fe cristiana: devoción a María y al Señor crucificado, celebraciones festivas de Navidad y Semana Santa, sacramentales como el agua bendita, procesiones y peregrinaciones a santuarios, imágenes, velas, palmas, respeto a los sacerdotes y devoción al papa, junto con ritos cósmicos a la madre tierra y celebraciones ancestrales y culto a los difuntos y antepasados.

Sin embargo, en muchos de ellos hay un divorcio entre la fe cristiana y la vida, una falta notable de formación cristiana bíblica y ética, un cristianismo más cultural que personal, asumido libre y responsablemente.

2.2. A partir del Vaticano II, recibido creativamente en Medellín, América Latina ha vivido una irrupción volcánica del Espíritu: denuncia profética de las estructuras injustas de pecado, opción por los pobres, comunidades eclesiales de base, obispos verdaderos santos padres de la Iglesia de los pobres, vida religiosa inserta en medios populares, compromiso social y político de laicos y laicas, también asumido en lo eclesial, martirio de obispos, presbíteros, vida 
religiosa, catequistas y agentes pastorales y pueblo sencillo que forman parte de los mártires inocentes. En este contexto nace la teología de la liberación. Pero estos grupos comprometidos no dejan de ser minorías abrahámicas, en expresión de Ellacuría.

En Latinoamérica, el diálogo ha sido más que con la primera Ilustración de la modernidad, con la segunda (que se puede tipificar de algún modo en la figura de Marx), preocupada por la justicia, los pobres, la economía, los oprimidos y excluidos. A esta sensibilidad por la justicia social se añade desde la década de los noventa una apertura por parte de la teología latinoamericana a la diversidad, a la llamada tercera Ilustración, a los indígenas y afroamericanos, a otras culturas y religiones, a las mujeres y jóvenes, a la ecología, al otro, a lo festivo y gratuito, a la razón simbólica. Figuras emblemáticas pueden ser no solo Lévinas y Ricoeur, sino Rigoberta Menchú y Eleazar López.

2.3. El cuadro estaría incompleto si no añadimos que muchos de entre los más pobres han acudido a Iglesias evangélicas, sobre todo pentecostales, en busca de la Palabra, del Espíritu, de una comunidad fraterna y cálida, de la conversión y de la sanación de sus múltiples heridas.

2.4. Otros grupos minoritarios con una ideología anticolonialista y fuertemente indigenista rechazan la fe cristiana que llegó con la colonia y regresan a sus religiones originarias, concebidas sobre todo como espiritualidades.

2.5. Aumenta también últimamente el sector entre los políticos, intelectuales, jóvenes, etc. que se proclaman agnósticos, indiferentes e incluso ateos.

Este mosaico de pluralismo religioso de América Latina explica que Aparecida hable de debilitación y crisis de fe y que se citen las lúcidas palabras de Benedicto XVI sobre la necesidad de una experiencia personal del encuentro con el Señor (Aparecida 12): "No se comienza a ser cristiano por una decisión ética o una gran idea, sino por el encuentro con un acontecimiento, con una Persona, que da un nuevo horizonte a la vida y, con ello, una orientación decisiva"4.

Otro autores, como Comblin, proponen una fe centrada en la tradición del Espíritu de Jesús y rechazan las estructuras religiosas que, centradas en el templo, el sacerdote y el sacrifico, han ido asfixiando al Evangelio ${ }^{5}$.

La pregunta es ¿llegará este tsunami del mundo occidental también a Latinoamérica? Mejor aún, ¿no es verdad que este tsunami ya ha llegado a América Latina, sobre todo a los jóvenes y a los sectores más abiertos a la modernidad y a la postmodernidad?

4. Benedicto XVI, Dios es amor, 1.

5. J. Comblin, O Espírito Santo e la tradição de Jesus, São Bernardo do Campo, 2012. 


\section{Algunos cuestionamientos}

La crisis de fe del mundo occidental, su indiferencia religiosa, su creciente agnosticismo y secularismo que nacen en gran parte del impacto de la modernidad ilustrada (primera Ilustración) no puede separarse del hecho histórico de que el progreso y el desarrollo de sus países, que les proporciona un bienestar material, ordinariamente hedonista y consumista, está estrechamente ligado al pasado colonial con América, Asia y África, al genocidio de pueblos indígenas, a la esclavitud africana y a la presencia actual de empresas transnacionales que siguen explotando al Tercer Mundo y destruyendo el medioambiente. ¿Cómo es posible encontrar a Dios, creer en Dios, confiar el él, cuando se vive con la ambición de vivir siempre mejor, de tener asegurado el futuro, se tiene miedo a perder estatus social, todo ello a costa de las víctimas? ¿Por qué el culto Occidente recurre a las drogas, tiene pánico a la enfermedad y a la vejez, convierte la muerte en un tabú e intenta ocultarla, como si esta vida terrena no tuviera nunca fin? ¿Puede encontrar a Dios el que pasa de largo junto al pobre, más aún cuando él es el responsable de su marginación? No basta la generosa beneficencia, ni la caridad asistencialista, que siempre se da en los países ricos, es necesario cuestionar el sistema.

Esta crisis de fe no es un problema puramente intelectual o filosófico, es un problema existencial que exige conversión. Esto vale también para los grupos secularizados de América Latina. Por esto, quienes desde la secularidad agnóstica se acercan a los pobres no están lejos del reino.

Por esto también quienes buscan el sentido de su vida en movimientos espirituales y esotéricos difícilmente llegarán al Dios de Jesús si su mística no es una mística de ojos abiertos (J. B. Metz), abierta a la solidaridad y a las víctimas. Esto vale también para los movimientos carismáticos y pentecostales de Latinoamérica.

De cara al Tercer Mundo, concretamente a América Latina, podemos preguntarnos - como hace Aparecida (n. 12) - si esta religiosidad popular podrá subsistir a la larga al embate del tiempo sin una tarea previa de evangelización y formación, sin una auténtica iniciación cristiana o catecumenado de adultos, sin un contacto directo con el Jesús histórico de los Evangelios y su anuncio del reino. ¿Qué será del futuro de los jóvenes?

Pero también la actitud creyente de los que tienen una actitud cristiana liberadora debe ser cuestionada. La teología de la liberación ¿no habrá acentuado las dimensiones - ciertamente irrenunciables - del compromiso cristiano, pero a costa de relegar un tanto las dimensiones de gratuidad, contemplación y esperanza escatológica? ¿No habrá fomentado, quizás sin darse cuenta, el voluntarismo, el paternalismo, el patriarcalismo e incluso un cierto milenarismo? El seguimiento del Jesús de Nazaret histórico, clave de bóveda de toda fe auténtica, 
¿no habrá olvidado la dimensión pneumatológica de la fe y de la existencia cristiana? ¿Es posible una cristología sin pneumatología? ¿No deberíamos completar la cristología y la eclesiología con una pneumatología desde América Latina?

También podemos preguntarnos si la crisis de fe de Occidente y su debilitación en América Latina no está ligada a las actuales estructuras de pecado de la Iglesia institucional. Ciertamente, el problema de fondo hoy no es eclesial, sino teologal, no es ante todo la Iglesia, sino la fe en Dios lo que se cuestiona, pero sin una conversión de la estructura eclesial es muy difícil a la larga mantener una actitud de fe cristiana.

La barca de la Iglesia se zarandea y fluctúa, como dice Benedicto XVI, pero no solo por el embate de los vientos huracanados que vienen del mundo, sino por las resquebrajaduras y hendiduras de la misma barca. Hemos de volver al mismo Espíritu que movió a Juan XXIII a convocar el concilio y convertirnos a la Iglesia que él mismo diseñó sobre todo en su discurso inaugural: una Iglesia de misericordia y no de anatemas, una Iglesia de los pobres centrada en Jesús de Nazaret y no una Iglesia poderosa y davídica, una Iglesia lugar de esperanza y no de profetas de calamidades, porque cree que el Espíritu del Señor guía no solo a la Iglesia, sino a toda la humanidad hacia el reino.

Hay que sentirse Iglesia aun en medio del invierno eclesial, pero cuando la Iglesia que debería ser sacramento transparente de Jesús se convierte en obstáculo para la fe, cuando la sal se vuelve insípida, es difícil y casi heroico seguir creyendo en el Señor Jesús. No es posible una nueva evangelización sin una conversión eclesial, de toda la Iglesia, al Evangelio, conversión de las personas pero también de las estructuras eclesiales que muchas veces han cristalizado en estructuras de pecado. Y la nueva evangelización que para el mundo occidental debe ser anuncio misionero y mistagógico a los ya no cristianos, en América Latina debe ser anuncio del Evangelio a los bautizados que deben profundizar su fe, acabar su catecumenado y ser discípulos y misioneros de Jesús, como propone Aparecida.

\section{Epílogo esperanzador}

En medio de las actuales dificultades y crisis de fe, no podemos olvidar la nube de testigos del pasado y del presente que han vivido la fe con profundidad $(\mathrm{Hb} 12,1)$. La verdadera historia de la Iglesia no es la historia de los papas, sino la historia de los santos. El Espíritu, afirma el Vaticano II, santifica, renueva y rejuvenece constantemente a la Iglesia y la conduce a la unión consumada con el Señor Jesús, enriquece a la Iglesia con dones jerárquicos y carismáticos ( $L G 4$ ), el Espíritu mantiene incólume la tradición del depósito de la fe. El Espíritu no abandona a la Iglesia de Jesús que es a la vez pecadora y santa. Cuando las comunidades primitivas introducen a la Iglesia en el tercer artículo del credo, quieren significar que la Iglesia está siempre bajo la acción del Espíritu 
dador de vida. Es el mismo Espíritu que nos hace clamar Abbá, Padre, y mantiene en la fe: nadie puede afirmar que Jesús es el Señor sin la fuerza del Espíritu (1 Cor 12,3) y nadie puede vivir la fe sin la ayuda del Espíritu. Nuestra actitud ha de ser mistagógica y epiclética a la vez, llena de esperanza, pidiendo que el Espíritu nos lleve a Jesús y a su seguimiento, a vivir plenamente su proyecto del Reino de Dios, la filiación divina y la fraternidad humana.

Concluyamos con la oración de la liturgia eucarística con la que encabezábamos esta reflexión: "Señor Jesucristo: no tengas en cuenta nuestro pecado, sino la fe de la Iglesia y, conforme a tu palabra, concédele la paz y la unidad. Tú, que vives y reinas por los siglos de los siglos. Amén”. 